\title{
Nonprofit enterprise in the performing arts
}

\author{
Henry Hansmann*
}

This article explores the reasons for the current dominance of the nonprofit form in the high-culture performing arts, and concludes that this development is a response to the need for price discrimination in that sector. The article develops a model of a nonprofit performing arts organization based on this analysis, and employs the model to explore, first, the consequences to be expected if such an organization adopts any of various plausible objective functions, and second, the circumstances in which subsidies to such an organization are justified and the way in which such subsidies should be structured.

\section{Introduction}

The live performing arts-including orchestral music, opera, theater, and ballet-are today in large part the product of nonprofit institutions. At the same time, there remain some segments of the performing arts, such as Broadway theater, that are vigorously for-profit (and profitable-see Moore, 1968, p. 12). Moreover, in the past profit-seeking institutions were apparently the rule rather than the exception in the performing arts; not only serious theater but even symphony orchestras were commonly proprietary. The dominance of nonprofit institutions in this industry is largely the product of recent decades, and is still far from complete. ${ }^{1}$

The existing literature offers no satisfying analysis of the factors that have caused this industry to become so heavily nonprofit, nor does it offer much in the way of a positive or normative perspective on the behavior of the nonprofit firms involved. Perhaps as a consequence, there also exists no well-articulated rationale for public subsidies to the performing arts, much less a coherent set of criteria by which to determine the appropriate amount and structure of such subsidies. This article addresses each of these issues.

\section{Why are the performing arts nonprofit?}

Donative financing. Nearly all nonprofit performing arts groups depend upon donations for a substantial fraction-commonly between one-third and one-

* University of Pennsylvania.

I am particularly indebted to Alvin Klevorick, Richard Nelson, Oliver Williamson, Sidney Winter, and the referees for helpful comments. Preparation of this paper was supported by a grant from the Program on Non-Profit Organizations at the Institution for Social and Policy Studies, Yale University.

${ }^{1}$ Among theaters, nonprofits are most commonly to be found in local and regional stock and repertory companies and off-Broadway, and are primarily a development of the period since World War II (Moore, 1968, pp. 16-20, 100; Baumol and Bowen, 1968, pp. 57-60). On the institutional history of symphony orchestras, see Mayernik (1976, p. 19). 
half - of their income (Baumol and Bowen, 1968, pp. 147-157). Because, for reasons that $I$ shall return to below, an organization that is dependent upon donations must generally be organized as a nonprofit, this pattern of financing provides a preliminary explanation for the predominance of the nonprofit form in this industry. But why are the performing arts so heavily financed by donations?

In other sectors such donative financing for nonprofits sometimes serves as a means for supporting the private production of public goods (Hansmann, 1980, pp. 848-854; Weisbrod, 1975). Consistent with this notion, it has frequently been argued that the performing arts exhibit substantial beneficial externalities, and that this in turn provides a rationale for both public and private subsidies (Baumol and Bowen, 1968, chapter 16; Netzer, 1978, chapter 2). For example, prominent cultural institutions bring prestige and tourism to both the city and the nation. Likewise, such institutions may, through indirect processes of cultural stimulus and transmission, ultimately contribute to the cultural experience even of people who do not attend their performances. But the ratio of such external benefits to the private benefits (that is, those enjoyed by members of the audience) for any performance is doubtless rather small-much smaller than the ratio of contributions to ticket receipts for the organizations involved. ${ }^{2}$ In any case, it does not appear that such external benefits are a major stimulus for the donations received by performing arts groups. Indeed, the evidence is strongly to the contrary, for it appears that the great bulk of the donations received by performing arts groups comes from people who actually attend the groups' performances, and not from the other members of the public who partake only of the prestige and other external benefits that the performances confer upon them. ${ }^{3}$

Another explanation commonly encountered is that donations are a private subsidy that enables ticket prices to be kept down to levels at which they can be purchased by people who could not otherwise afford them. Undoubtedly this is part of the motivation of at least some who contribute. Yet the vast majority of people who attend the performing arts are quite well-heeled (Baumol and Bowen, 1968, chapter 4). Surely it is doubtful that the performing arts are organized on a nonprofit basis primarily to provide a vehicle whereby the rich can subsidize the merely prosperous.

The situation, then, is at first appearance rather paradoxical. Here we have a service, essentially private in character, financed partly by donations and partly by revenue from ticket sales. Yet the people who donate are also the people who attend the performances - that is, who buy tickets. Moreover, it appears that performing arts organizations commonly price their tickets so low that they operate well within the inelastic portion of their demand curve, thus failing to maximize receipts from ticket sales (Baumol and Bowen, 1968, pp.

${ }^{2}$ Moore (1968, chapter 8 ) and Peacock (1976) are also skeptical about the magnitude of the public benefits involved.

As noted below, however, a performing arts production is to an important extent a public good for those individuals who are among the audience. Thus, if someone who has already purchased a subscription to the Metropolitan Opera makes a donation to that organization, the improvement in the quality of the performances that the donation permits will be enjoyed as a public good by all others who also hold subscriptions.

${ }^{3}$ Direct data on the proportion of donations coming from audience members are apparently unavailable. Some indication is provided, however, by the evidence, discussed below, indicating that a substantial percentage of those who attend also contribute. 
272-278). Why do these organizations seek to extract part of their revenues from the audience through donations, rather than simply by raising their ticket prices?

Price discrimination. These phenomena all become understandable if we simply recognize contributions in the performing arts as a form of voluntary price discrimination. ${ }^{4}$

The considerable costs of organizing, directing, rehearsing, and providing scenery and costumes for a performing arts production are essentially fixed costs, unrelated to audience size. Marginal costs are correspondingly low: once one performance has been staged, the cost of an additional performance is relatively small, and, as long as the theater is unfilled, the cost of admitting another individual to a given performance is close to zero. At the same time, the potential audience for high-culture live entertainment is limited even in large cities; consequently, for any given production there are typically only a few performances over which to spread the fixed costs - often three or fewer for an orchestral program and only several times that for opera, ballet, and many theatrical productions. Thus, fixed costs represent a large fraction of total costs for each production. ${ }^{5}$

The result is that if ticket prices are set close to marginal cost, admissions receipts will fail to cover total costs. Indeed, it appears likely that for most productions staged by nonprofit performing arts groups the demand curve lies below the average cost curve at all points, so that there exists no ticket price at which total admission receipts will cover total costs.

If the organizations involved could engage in price discrimination, they might be able to capture enough of the potential consumer surplus to enable them to cover their costs. ${ }^{6}$ In the performing arts, however, the effectiveness of discriminatory ticket pricing is limited by the difficulty of identifying individuals or groups with unusually inelastic demand, and by the difficulty of making admission tickets nontransferable. To be sure, a degree of price discrimination can be, and often is, affected by charging higher prices for more desirable seats: if those patrons whose demand for a given performance is most inelastic also have the strongest relative preference for good seats over bad seats, then it may well be possible to establish a price schedule that will channel those with inelastic demand into the good seats at high prices,

\footnotetext{
${ }^{4}$ Moore (1968, pp. $\left.120-121\right)$ also alludes briefly to contributions as a means of price discrimination, though he does not pursue the issue.

"It is difficult to obtain useful data comparing fixed costs with variable costs for productions by performing arts groups. Existing studies of economies of scale in the nonprofit performing arts (Baumol and Bowen, 1968, chapter 8; Globerman and Book, 1974) simply correlate cost per performance with the total number of performances per year for different organizations (e.g., symphony orchestras or theater groups) without taking into account the number of different productions represented by those performances. Data on Broadway theater assembled by Moore (1968, chapter 3) are, however, suggestive; they show that, for the 1960-1961 season, weekly operating cost-i.e., the (variable) cost of a week's performances-for a show was, on average, less than a fifth as large as the (fixed) cost of producing the show.

${ }^{6}$ Here and in what follows I assume that nonprofit performing arts firms have some degree of monopoly power, and thus face downward-sloping demand curves. This is in keeping with the observation that demand is limited and fixed costs are high, thus presumably making competition unworkable. It is also in keeping with the very limited competition that in fact prevails among the nonprofit performing arts; even New York City supports only one major symphony orchestra, two substantial opera companies, and a handful of (highly differentiated) dance groups.
} 
and those with more elastic demand into the inferior seats at lower prices. ${ }^{7}$ This device is limited, however, by the strength of the preference for good seats over bad that is exhibited by patrons whose demand for performing arts productions is relatively inelastic. ${ }^{8}$

Yet, even if it is difficult to establish effective price discrimination via ticket pricing, it is still possible to ask individuals simply to volunteer to pay an additional amount if the value they place upon attendance exceeds the price charged for admission. And this, in effect, is the approach taken by nonprofit organizations in the performing arts.

Of course, the services paid for by a voluntary contribution to a performing arts group are public goods for all individuals who attend the group's performances, ${ }^{9}$ and there is a clear incentive to be a free rider. As a consequence, many people contribute nothing, and presumably most of those who do contribute give something less than their full potential consumer surplus. Nevertheless, many individuals do contribute when confronted with solicitations pointing out that, in the absence of contributions, the organizations on which they depend for entertainment may disappear. Indeed, it appears that roughly $40 \%$ of those who attend the live performing arts contribute at least occasionally (Baumol and Bowen, 1968, pp. 307-308).

The fact that contributions to nonprofit performing arts groups are deductible under the federal income tax is undoubtedly important in reducing the incentive to be a free rider (see Section 4). Donors' committees and other organizational strategies are also presumably important in creating incentives and social pressure to help overcome free-rider behavior ${ }^{10}$ - though here, as in the case of many other private nonprofits providing public goods (such as those devoted to political causes, environmental protection, and medical research), a surprisingly large number of individuals seem willing to respond even to impersonal solicitations received by mail.

Those areas of the performing arts that are organized on a profit-seeking basis typically differ from the areas that are nonprofit in having a much larger audience over which to spread the fixed costs of a production, so that the ratio of fixed to variable costs is relatively small, and there is consequently little difference between marginal and average cost. Broadway shows, for example, typically run for several hundred performances (Moore, 1968, chapter 1 and Table A-6). Similarly, although the cost of producing a movie commonly runs into many millions of dollars, the audience over which that cost can be spread is enormous; consequently, only about $15 \%$ of movie theater receipts is devoted to covering production costs (Gordon, 1976). Therefore, substantial price dis-

${ }^{7}$ See Winter's (1968) analysis of essentially the same issue in a different context. It also follows from Winter's analysis that, when constructing a new theater, there may well be gains to be had from creating a high ratio of bad seats to good seats, even if it would be as cheap or cheaper to construct a larger proportion of good seats for the same total capacity.

${ }^{8}$ Likewise, the performing arts are not well situated to take advantage of the type of twopart tariffs described by Oi (1971), since many people wish to attend only one performance by a given organization and since it is difficult to make tickets nontransferable.

${ }^{9}$ See note 2 .

${ }^{10}$ To some extent, contributions undoubtedly represent an effort to buy recognition and status. Many organizations in the performing arts exploit this motivation quite consciously by publicizing the names of donors and by arranging special social events for them. But the development of the performing arts as a locus for such conspicuous giving seems most probably a consequence rather than a cause of their nonprofit donatively-financed status. 
crimination - and, in particular, voluntary price discrimination - is not necessary for survival, and thus the nonprofit form loses its special comparative advantage. Since, in the absence of such a comparative advantage, nonprofit firms seem, for a number of reasons, to be less efficient producers than forprofit firms (Hansmann, 1980, pp. 877-879), it is to be expected that competition should favor for-profit firms in these areas.

Note that this analysis also suggests an explanation for the observed tendency, noted above, of nonprofit performing arts organizations to price their tickets below the level that maximizes total admissions receipts-much less the level that maximizes receipts in excess of variable costs. It seems likely that an increase in ticket prices will generally lead to a decrease in donations, since the total reservoir of consumer surplus from which those donations derive will decrease. ${ }^{11}$ Consequently, total revenue - which includes both ticket sales receipts and donations - will be maximized at a lower ticket price than that which maximizes admissions receipts alone.

Some historical evidence. The analysis offered here may also help to explain why nonprofit organizations have become increasingly prominent in the performing arts through the years. Because productivity in the live performing arts has not grown at the same pace as in the economy at large, the cost of performing arts productions has increased disproportionately to that of most other goods (Baumol and Bowen, 1968, chapters 8, 9). As a consequenceand also, undoubtedly, because of competition from new entertainment media such as movies, radio, and television-demand for the live performing arts has remained small, and even, by some measures, declined (Baumol and Bowen, 1968, chapter 3). Beyond this, however, it appears that fixed costs have consistently risen at a faster rate than have variable costs, and thus have come to represent an increasingly large share of total costs. ${ }^{12}$ These developments have presumably given nonprofit organizations, with their access to the form of price discrimination described above, an increasing advantage over their profit-seeking counterparts, which are dependent upon ticket sales alone to cover both fixed and variable costs.

The nonprofit form. Thus far I have been assuming that even if an individual is willing to donate money to a performing arts group above and beyond the amount he must pay for a ticket, he will do so only if the organization involved is nonprofit, and not if it is profit-seeking. That is, only nonprofits will have access to the form of voluntary price discrimination I have been describing. Although the reason that this is so may seem obvious, it is perhaps worth

${ }^{11}$ Baumol and Bowen (1968, p. 277) report that their interviews with managerial personnel in fact revealed a fear that increased ticket prices would lead to reduced contributions. Although Baumol and Bowen devote little attention to this relationship between contributions and ticket prices, they offer no alternative explanation for the tendency to set prices at a level where demand is inelastic, other than the possibility that management feels that by keeping prices low they are fulfilling a social obligation to make the performing arts available to as much of the populace as possible. The behavior of a firm that has the latter objective, yet is dependent upon donative financing, is explored in Sections 3 and 4 below.

${ }^{12}$ In terms of constant dollars, average production costs for Broadway theater increased by $236 \%$ between 1927 and 1961, while weekly operating costs increased by only $80 \%$. This relative increase in production costs was evidently responsible for the fact that the length of run required for a Broadway show to make a profit roughly tripled over this period (Moore, 1968, pp. 11-12, 34). 
being somewhat more explicit. A more detailed discussion appears in my earlier article (1980) on nonprofit enterprise.

When a contributor gives money to, say, an opera company, he is actually trying to "buy" something - namely more and better opera. Such contributions differ from ordinary prices paid for goods and services in that the latter are clearly and directly conditioned upon specific, identifiable activity on the part of the person to whom the price is paid, such as delivering certain goods to the purchaser or permitting him to occupy a given seat at a given performance in a given theater. That is, when one pays what we usually term a "price," one commonly knows whether the services offered in exchange were performed satisfactorily and can seek redress if they were not. But with those payments that we term "donations," things are more difficult.

Suppose that an opera company solicits donations and asserts that it will devote all funds received to the production of opera. And suppose that an individual, in reliance on that representation, contributes. How does he know that his money was in fact devoted to opera productions? His only meaningful assurance lies in the opera company's nonprofit form of organization. For a nonprofit organization is in essence an organization that is barred by law from distributing net earnings - that is, anything beyond reasonable remuneration to persons who exercise control over it, such as its directors, officers, or members. Consequently, one can make contributions to such an organization with some assurance that they will be devoted to production of the organization's services. With a profit-seeking organization it is difficult to obtain such assurance where, as with the performing arts, the connection between an individual contribution and increased production of services is not directly observable.

Summary. In sum, it appears that nonprofit firms in the performing arts, like their for-profit counterparts, serve primarily to sell entertainment to an audience. The difference between the two types of firms lies simply in the way in which payment is received. But the difference has significant consequences. The nonprofit firm, through its access to voluntary price discrimination, is viable in segments of the performing arts market where for-profit firms cannot survive. ${ }^{13}$

\section{The economic behavior of performing arts organizations}

- The firm's objectives. Presumably profit maximization is excluded as an objective for any legitimate nonprofit; consequently, the organization must select other goals. This choice of goals may be in the hands of any one or more of several individuals or groups, including performers, directors, producers, professional managers, substantial donors, and donors' committees.

${ }^{13}$ There are areas other than the performing arts in which similar factors seem to be at work. For example, one of the most interesting and most obvious examples of the type of voluntary price discrimination described here is provided by New York's Metropolitan Museum of Art, which requires that every visitor pay some amount to gain admission, but leaves each visitor entirely free to determine how much to pay. In this connection it should be noted that museums are seemingly characterized by an even higher ratio of fixed costs to marginal costs than are the performing arts, yet, like performing arts groups, are in a relatively poor position to implement nonvoluntary price discrimination. 
One likely possibility - particularly if control over the organization lies with professionals who have devoted their careers to a particular art formis that the organization will place special emphasis upon the quality of its performances. Such a pursuit of quality might take either of two forms. First, the organization could seek to make its production of any given work as impressive as possible, for example by hiring exceptionally skilled performers, constructing lavish stage sets, and so forth. Second, the organization could choose to produce works that appeal only to the most refined tastes, avoiding the more popular items in the repertoire.

Alternatively, a performing arts group might feel a mission to spread culture to as broad a segment of the populace as possible, and consequently seek to maximize attendance for any given production. Or, as yet another possibility, control might lie in the hands of managers who are organizational empirebuilders, and who seek simply to maximize the total budget they administer.

In what follows I shall develop a simple model of a performing arts organization, based on the analysis in Section 2, that permits exploration of the consequences of pursuing each of the alternative objectives just described. The exercise is of interest not just as a matter of positive theory but for normative purposes as well. At present there is considerable debate concerning the way in which the management of performing arts organizations should exercise the substantial degree of discretion they enjoy. A recurrent theme in this debate is the choice between quality of production and refinement of taste on the one hand, and outreach to broader audiences - via lower prices and appeal to more popular tastes - on the other (Brustein, 1978).

In the discussion of the model the term "quality" will generally be used in the first of the two senses described here (lavishness of production). As noted below, however, the model can be interpreted in terms of the second form of quality (appeal to refined tastes) as well.

The basic model of the firm. The size of the audience that the organization attracts for all performances of a given production (or, alternatively, for all of its productions combined) will be denoted by $n,{ }^{14}$ while $q$ represents the quality of the work(s) performed. The ticket price $P$ charged for admission to a performance is expressed by the inverse demand function $P=P(n, q), P_{n}<0$, $P_{q}>0$. Total donations received by the firm are taken to be inversely related to $P$ and directly related to $q, D=D(P, q), D_{p}<0, D_{q}>0$. Expressed in terms of $n$ and $q, D=D[P(n, q), q]=D(n, q), D_{n}>0, D_{q} \gtreqless 0$. A special case is

$$
D=\delta\left\{\int_{0}^{n} P(v, q) d v-n P(n, q)\right\} .
$$

This is the donation function that would result if all donations were to come from individuals who attend performances, and if such individuals were to

${ }^{14}$ In Broadway theater each production is usually organized as a separate "firm" (Baumol and Bowen, 1968, p. 20). Most nonprofit performing arts organizations, in contrast, are relatively permanent and produce a large number of productions. (This difference in structure is presumably explainable at least in part by the need for nonprofit groups to develop strong and stable reputations that will provide assurance to potential donors.) Since I shall not be concerned with the effect that one production has upon demand for another, the number of productions that a given organization undertakes will not be important here. 
donate, on average, a given fraction, $\delta$, of the consumer surplus that they would otherwise enjoy at price $P$ and quality $q \cdot{ }^{15}$

Total costs are given by $C=C(n, q), C_{n}>0, C_{q}>0$. Since the firm is nonprofit, net revenue, $N R$, is constrained to be zero:

$$
N R \equiv n P(n, q)+D(n, q)-C(n, q)=0 .
$$

The firm's objective function is given by $U=U(n, q), U_{n} \geq 0, U_{q} \geq 0$, $U_{n n} \leq 0, U_{q q} \leq 0$. For the pure quality maximizer $U(n, q)=q$; for the pure audience maximizer $U(n, q)=n$; and for the budget maximizer $U(n, q)=C(n, q)$.

The firm maximizes $U(n, q)$ subject to $(2) .{ }^{16}$ The Lagrangian is

$$
\phi=U(n, q)+\lambda[n P(n, q)+D(n, q)-C(n, q)] .
$$

Assuming an interior solution, ${ }^{17}$ the first-order conditions are (2) and

$$
\begin{aligned}
& N R_{q} \equiv n P_{q}+D_{q}-C_{q}=-\frac{U_{q}}{\lambda} \\
& N R_{n} \equiv P+n P_{n}+D_{n}-C_{n}=-\frac{U_{n}}{\lambda},
\end{aligned}
$$

where $N R_{q} \equiv \partial N R / \partial q$, etc., and $\lambda$ is the Lagrange multiplier.

The slope of the nonprofit constraint (2) at the point at which the firm operates is, from (4) and (5):

$$
\left.\frac{d q}{d n}\right|_{N R=0}=-\frac{N R_{n}}{N R_{q}}=-\frac{U_{n}}{U_{q}} .
$$

For the quality maximizer, for which $U_{n}=0$ and $U_{q}=1$, this slope is zero; for the audience maximizer, for which $U_{n}=1$ and $U_{q}=0$, the slope is $-\infty$. These points are shown, respectively, as $a$ and $b$ in Figure 1 . If the firm values both quality and audience size, so that $U_{n}>0$ and $U_{q}>0$, then the firm will operate at a point such as point $c$ on the arc between points $a$ and $b$.

Consumer surplus, which I shall denote by $S$, and which I shall use as a measure of welfare (see Willig, 1976), is given by ${ }^{18}$

$$
S=\int_{0}^{n} P(v, q) d v-C(n, q) .
$$

This expression is at a maximum with respect to $q$ and $n$ when

$$
\begin{aligned}
& S_{n}=P-C_{n}=0 \\
& S_{q}=\int_{0}^{n} P_{q}(v, q) d v-C_{q}=0 .
\end{aligned}
$$

${ }^{15}$ An important issue that will be avoided here is the degree to which an organization can and will use some of its income to solicit further donations.

${ }^{16}$ See Newhouse (1970) and Feldstein (1971) for other models of nonprofit firms (in particular, hospitals) with similar objective functions.

${ }^{17}$ The second-order condition, both here and for the altered models of the firm below, is

$$
\lambda\left[2 N R_{n} N R_{q} N R_{n q}-N R_{n}^{2} N R_{q q}-N R_{q}^{2} N R_{n n}\right]+2 N R_{n} N R_{q} U_{n q}-N R_{n}^{2} U_{q q}-N R_{q}^{2} U_{n n}>0 .
$$

${ }^{18}$ Note that, by virtue of the nonprofit constraint (2), (monetary) producer surplus is necessarily zero here. For simplicity I ignore, in computing $S$, changes in the mangers' utility $U(n, q)$. 
FIGURE 1

FIRM BEHAVIOR AND WELFARE OPTIMIZATION

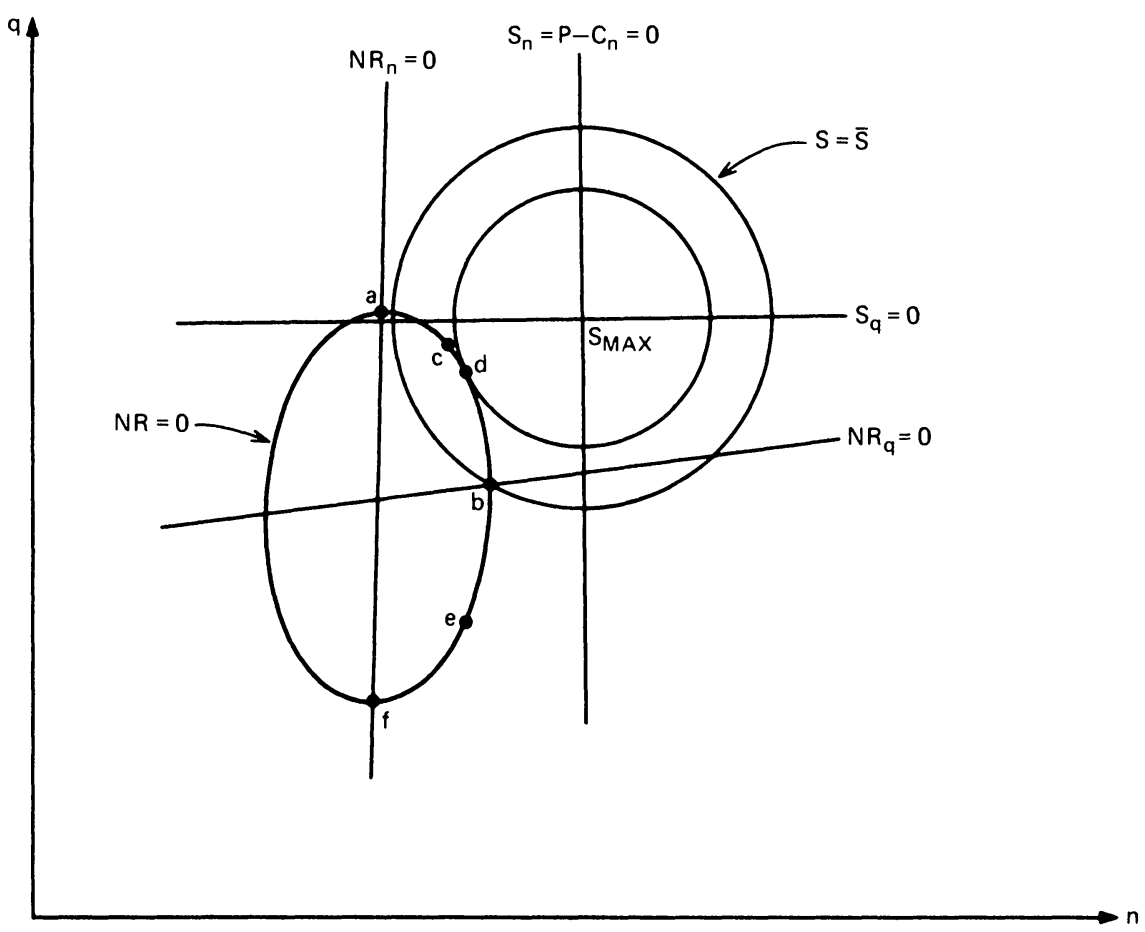

Condition (8) says simply that price should be set equal to marginal cost. Condition (9) says that quality should be at a level at which the marginal cost of greater quality just equals the marginal valuation put upon quality by the audience as a whole. There is no reason to believe, however, that these marginal conditions are consistent with the financial constraints under which the nonprofit firm must operate. Thus, for example, price can be set as low as marginal cost only if donations are sufficiently large to cover fixed costs.

More relevant to evaluating the performance of the nonprofit firm is the constrained social optimum determined by maximizing (7) subject to the nonprofit constraint (2). The resulting Lagrangian is $\theta=S+y N R$, where $y$ is a Lagrange multiplier. The first-order conditions are

$$
\begin{aligned}
& \frac{\partial \theta}{\partial n}=S_{n}+y N R_{n}=P-C_{n}+y N R_{n}=0 \\
& \frac{\partial \theta}{\partial q}=S_{q}+y N R_{q}=\int_{0}^{n} P_{q}(v, q) d v-C_{q}+y N R_{q}=0 .
\end{aligned}
$$

The slope of the constraint, $N R=0$, at the constrained social optimum, shown as $d$ in Figure 1 , is therefore

$$
\frac{N R_{n}}{N R_{q}}=-\frac{P-C_{n}}{\int_{0}^{n} P_{q}(v, q) d v-C_{q}}
$$

The nonprofit firm will be operating at the social optimum, given its 
financing constraints, only if the slope given in (12) is equal to that in (6), i.e., only if, at the $(n, q)$ combination chosen by the firm,

$$
\frac{U_{n}}{U_{q}}=\frac{P-C_{n}}{\int_{0}^{n} P_{q}(v, q) d v-C_{q}}
$$

Whether or not this condition is satisfied will depend upon the firm's objective function as well as upon the cost and demand functions that the firm faces, as the following discussion shows.

The quality-maximizing firm. For the quality-maximizing firm, for which $U_{q}=1$ and $U_{n}=0$, condition (13) will hold, and the firm will be operating at the constrained optimum, only if $P=C_{n}$. From condition (5), however, it follows that for the quality maximizer

$$
N R_{n} \equiv P+n P_{n}+D_{n}-C_{n}=0 .
$$

That is, for any given quality level, $q$, the quality maximizer will choose the audience size, $n$, that maximizes its net revenue, which it can in turn use to purchase more quality. This is consistent with the condition that $P=C_{n}$ only if $D_{n}=-n P_{n}$, which is to say that, at the margin, when audience size increases (because of a decrease in ticket price) members of the audience increase their donations by precisely as much as their ticket prices decrease. ${ }^{19}$ In terms of the donation function (1), for example, this will be the case only if $\delta=1$-that is, only if audience members donate $100 \%$ of their consumer surplus to the firm. In the face of less generous - but more plausible-contribution levels, the firm will sacrifice audience size too heavily for the sake of quality.

The audience-maximizing firm. For the audience maximizer $U_{q}=0$; it therefore follows from (4) that

$$
N R_{q}=n P_{q}+D_{q}-C_{q}=0 .
$$

That is, for any given audience size, the audience maximizer will choose that level of quality that maximizes net revenues, since those revenues can be used to reduce ticket prices, which will in turn attract a larger audience.

From (13), we see that the audience maximizer will operate at the constrained optimum only if $S_{q}=0$ so that condition (9) holds. For (9) to obtain when the firm is an audience maximizer — and hence (15) holds - we must have:

$$
\frac{1}{n} \int_{0}^{n} P_{q}(v, q) d v-P_{q}=\frac{D_{q}}{n} .
$$

If $D_{q}=0$, then (16) is equivalent to the condition shown by Spence (1975) and Sheshinski (1976) to be necessary for a profit-maximizing monopolist

${ }^{19}$ This is a necessary but not a sufficient condition for the quality maximizer to operate at the constrained social optimum. If, for example, the locus $S_{q}=0$ lies below the locus $N R_{q}=0$ the conditions for which are explored below-it is possible that the constrained social optimum will be at the quality-minimizing point $f$ rather than the quality-maximizing point $a$ in Figure 1 when donative behavior is such that $D_{n}=-n P_{n}$.

A similar qualification applies to the discussion of the audience maximizer below. 
to select the socially optimal level of quality for its product: the valuation put upon increases in quality by the average member of the audience must equal the valuation put upon such increases by marginal members of the audience.

The interesting fact established by (16), however, is that the responsiveness of donations to changes in quality, $D_{q}$, can serve to reduce the incentive for the firm to choose a nonoptimal level of $q$ in those cases where the average and marginal audience members value quality differently, because donations presumably reflect primarily the preferences of inframarginal-and hence more typical-audience members. This point appears clearly if we rewrite condition (16) using the donation function (1):

$$
(1-\delta)\left[\frac{1}{n} \int_{0}^{n} P_{q}(v, q) d v-P_{q}\right]=0 .
$$

Here we see that the firm's choice of quality moves closer to the optimum, not only as marginal and average consumer valuations of quality converge, but also as $\delta \rightarrow 1$.

If donations respond as in (1), and if $\delta<1$, it is easy to show that, as with the profit-maximizing monopolists considered by Spence and Sheshinski, when marginal consumers value quality increases less than does the average consumer-i.e., when $P_{q n}<0$ - the audience maximizer will choose a level of $q$ below that which represents the constrained social optimum, while the reverse is true if $P_{q n}>0$. (In diagrammatic terms, if $P_{q n}<0$, the locus $S_{q}=0$ lies above the locus $N R_{q}=0$, as in Figure 1, while the reverse is true if $P_{q n}>0$, as in Figure 2 in Section 5; the two loci coincide if $P_{q n}=0$.)

The budget-maximizing firm. For the budget maximizer $U(n, q)=C(n, q)$ and, as noted earlier, such a firm will operate at a level of $(n, q)$ such as that indicated by point $c$ in Figure 1, intermediate between the points chosen by the quality maximizer and the audience maximizer. From the preceding analysis of the audience maximizer, it follows that generally the budget maximizer will operate at or near the constrained social optimum only if consumer preferences for quality are such that $P_{q n}<0$.

Some comparisons. Of the three types of firms analyzed above, which is likely to perform most in accord with maximal social welfare? There is, interestingly, no simple response - the answer evidently depends heavily upon the nature of consumer demand and donative behavior.

If $P_{q n} \geq 0$, the audience maximizer will unambiguously turn in the best performance - at least if donations respond as modeled in (1). In the intuitively more plausible case where $P_{q n}<0$, however, the budget maximizer or the quality maximizer might perform better; their higher emphasis on quality compensates for the atypically low taste for quality that characterizes the marginal consumer, whose tastes dictate the prices at which tickets can be sold.

Quality as refinement of taste. The discussion so far has proceeded largely on the assumption that the variable $q$ represents the first type of quality discussed earlier, namely the lavishness with which any given work is produced. The model as developed above can, however, alternatively be interpreted with 
$q$ representing the degree to which the firm's productions appeal to highly refined tastes. Viewing the model in these terms, one might assume that the amount to be spent on performers, sets, costumes, the director's fee, etc., are fixed, leaving the firm free to choose only among works that can be staged with these given resources. A quality-maximizing firm would then be one that chooses works that appeal to a highly cultured, but also small, audience. ${ }^{20}$ In terms of the model, this means that $C_{q}=0$ and, beyond a certain minimal level of $q, P_{q}<0 .{ }^{21}$

The preceding analysis and conclusions remain valid for this alternative interpretation of $q$ and the accompanying change of values for $C_{q}$ and $P_{q}$. Note, however, that with $C_{q}=0$ the budget maximizer and the audience maximizer are identical.

\section{The rationale for subsidies}

If the analysis of Section 2 is correct, then the most compelling rationale for providing subsidies to performing arts organizations is not that they produce external benefits or serve as a vehicle for redistribution of income-which are the rationales that have been the primary focus of discussion to date (see Baumol and Bowen, 1968, chapter 16; Netzer, 1978, chapter 2)-but rather that the high fixed costs that such firms face will, in the absence of a subsidy, force them to set prices too high to satisfy marginal criteria for efficiency, and may well make them unviable. ${ }^{22}$

As in the case of all such subsidies, there is a substantial conflict between equity and efficiency. Although the subsidy may help establish efficient pricing, the individuals who consume the services financed by the subsidies are likely to constitute only a small fraction of the people who pay for them-at least if the source of the subsidy is the public fisc. Indeed, given that the class of people who attend the performing arts is not only small but unusually prosperous and geographically concentrated, the problem of equity raised by subsidies is particularly acute.

\section{When is a subsidy efficient?}

If a performing arts organization, in the absence of a subsidy, is setting its ticket prices well above marginal cost to cover the fixed costs associated

${ }^{20}$ See Baumol and Bowen (1968, pp. 253-257) for a discussion of the desire of performing arts groups to perform contemporary works, and the adverse consequences this has for demand.

${ }^{21}$ The level of $q$ at which $P_{q}(n, q)$ reaches zero should presumably depend on $n$. For very low values of $n$, at which point one is dealing only with true enthusiasts, $P_{q}$ might even remain positive for all values of $q$.

${ }^{22}$ Moore (1968, pp. 120-121, 122) also makes a brief, though puzzlingly dismissive, reference to "price discrimination" as a possible rationale for performing arts subsidies, by which he evidently means something like the declining-average-cost rationale suggested here.

I should emphasize that I am speaking here only of subsidies for the performance of existing works. Subsidies to authors and composers for the creation of new works are an entirely different matter. It is often extremely difficult for an artist to capture for himself even a small fraction of the benefits society derives from his work, and thus there is much to be said for subsidizing them. Since public acceptance of new works often lags considerably behind their creation, and since it is probably helpful to the artist to see his work performed when he produces it, this may also lead to some justification for subsidies to performing arts groups that are specifically earmarked for performance of new works. (The Ford Foundation, for example, has sometimes pursued this course; see Ford Foundation (1974, Vol. 1., p. 42).) 
with its productions, then it is possible that a subsidy will lead to more efficient levels for price and output. But this need not be the case. As the following discussion shows, a subsidy can in some cases lead to even greater inefficiency, quite apart from its likely adverse distributional consequences.

The general model. For the moment I shall confine the analysis to a lumpsum subsidy. Similar results for other kinds of subsidies follow directly from the analysis in later sections.

Consider the same firm modeled above, except that its revenue now includes a lump-sum subsidy, $L$. Thus the firm now seeks to maximize $U(n, q)$ subject to

$$
N R=n P(n, q)+D(n, q)+L-C(n, q)=0 .
$$

Assuming an interior solution, the first-order conditions for a constrained maximum with respect to $n$ and $q$ are unchanged from (4) and (5) above; the constraint (18) becomes the third condition. In diagrammatic terms, the consequence of increasing the subsidy, $L$, is to enlarge the closed curve representing the nonprofit constraint, as shown in Figure 2. The loci $N R_{n}=0$ and $N R_{q}=0$ remain unchanged. The quality maximizer, which operated at point $a$ without the subsidy, will operate with the subsidy at point $\hat{a}$, while the audience maximizer will shift from $b$ to $\hat{b}$.

To determine whether such shifts will lead to an increase in social welfare, we can differentiate (7) with respect to $L$,

$$
\frac{d S}{d L}=S_{q} \frac{d q}{d L}+S_{n} \frac{d n}{d L}=\left[\int_{0}^{n} P_{q}(v, q) d v-C_{q}\right] \frac{d q}{d L}+\left[P-C_{n}\right] \frac{d n}{d L},
$$

FIGURE 2

THE EFFECT OF A LUMP-SUM SUBSIDY

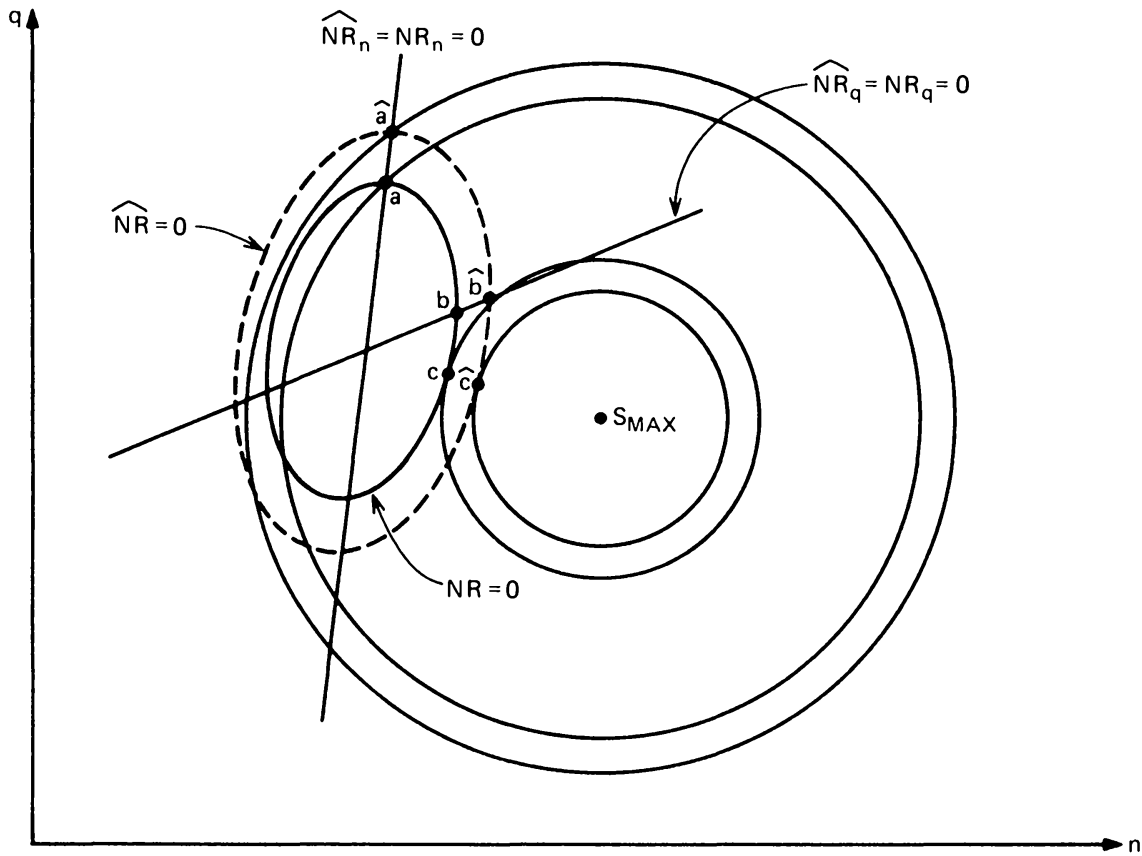


and then evaluate (19) by using simple comparative statics to determine $d q / d L$ and $d n / d L$ for the firm.

For simplicity, I shall confine the analysis to the polar cases of the audience-maximizing firm and the quality-maximizing firm.

The quality maximizer. Consider first the quality maximizer. Setting $U_{q}=1$ and $U_{n}=0$ in (4) and (5), and totally differentiating (4), (5), and (18) with respect to $L$ yield:

$$
\begin{aligned}
& \frac{d n}{d L}=\frac{N R_{q n}}{N R_{q} N R_{n n}} \\
& \frac{d q}{d L}=\frac{-1}{N R_{q}} .
\end{aligned}
$$

Since the quality maximizer operates where $N R_{q}<0$, it follows from (21) that $d q / d L>0$ : increasing the subsidy, $L$, will, as expected, cause the quality maximizer to raise its quality level.

Whether an increase in the subsidy will also generally lead to an increase in the size $n$ of the audience that sees a given production is less certain. Since $N R_{q}<0$, and since, if the second-order condition holds, $N R_{n n}<0$, the sign of $d n / d L$ is the same as that of $N R_{q n}$, which equals $P_{q}-C_{q n}+(1-\delta) n P_{q n}$ when the donation function is given by (1). Given that $P_{q}>0, C_{q n}>0$ (if we are again speaking of quality in the first of the two senses defined in Section $3^{23}$ ), and $P_{q n} \lesseqgtr 0$, it follows that $N R_{q n}$, and thus $d n / d L$, are indeterminate in sign. Conditions favorable to an audience increase are: (1) a low value of $C_{q n}$ (increasing the audience does not much increase the cost of quality), and (2) $P_{q n}$ $>0$ (the new (marginal) audience members admitted have an unusually strong taste for quality).

Turning to the welfare implications of such behavior, we have $S_{n}=P-C_{n}$, and as discussed in Section 3 this will always be nonnegative for the quality maximizer. Thus, increases in audience size are unambiguously desirable for the quality maximizer. On the other hand, the desirability of an increase in quality is less clear; using (1), we have:

$$
S_{q}=\int_{0}^{n} P_{q}(v, q) d v-C_{q}=(1-\delta)\left[\int_{0}^{n} P_{q}(v, q) d v-n P_{q}\right]-\frac{1}{\lambda} .
$$

Since $\lambda>0$, this expression will be unambiguously negative whenever $P_{q n}$ $>0$. Only where $P_{q n}<0$ can $S_{q}$ be positive.

The overall effect on welfare of increasing the subsidy, $L$, is therefore indeterminate. The condition required for the first term in (19), $S_{q}[d q / d L]$, to be positive, $P_{q n}<0$, is simultaneously conducive to a low, and possibly negative, value for the second term, $S_{n}[d n / d L]$. It is easy, however, to construct examples in which increasing $L$ decreases welfare, even though the quality maximizer's ticket price in the absence of a subsidy is well above marginal cost. ${ }^{24}$ Such a case is illustrated in Figure 2 (which is drawn so that $P_{q n}>0$ ), where $\hat{a}$ lies on a lower iso-social-welfare curve than does $a$.

${ }^{23}$ As in Section 3, the results here and below can be reinterpreted for the case in which $q$ represents quality of the second type by assuming, instead, that $C_{q}=0$ and that, beyond some level of $q, P_{q}<0$.

${ }^{24}$ As an example, consider a quality-maximizing firm that faces a demand function 
The audience maximizer. Turning to the audience maximizer we have

$$
\begin{aligned}
& \frac{d n}{d L}=\frac{-1}{N R_{n}} \\
& \frac{d q}{d L}=\frac{N R_{q n}}{N R_{n} N R_{q q}} .
\end{aligned}
$$

By logic parallel to that employed in analyzing the quality maximizer, it follows that $d n / d L>0$, while the sign of $d q / d L$ is the same as that of $N R_{q n}$, and therefore ambiguous.

From (19), an increase in $n$ will be desirable as long as $P>C_{n}$. Using (1), the $S_{q}$ term in (19) becomes

$$
S_{q}=(1-\delta)\left[\int_{0}^{n} P_{q}(v, q) d v-n P_{q}\right] .
$$

Thus $\operatorname{sgn} S_{q}=-\operatorname{sgn} P_{q n}$. If follows that $S_{q}[d q / d L]$, and hence (19), are ambiguous in sign: it is possible that a lump-sum grant to an audience-maximizing firm, as to a quality maximizer, can lead to a reduction in welfare, even when, in the absence of a subsidy, the firm is operating where $P>C_{n} \cdot{ }^{25}$ (Figure 2 illustrates a case where $d S / d L>0$.)

\section{Donation subsidies}

In fact, subsidies to the performing arts are frequently not lump-sum in nature, but rather take the form of matching grants for donations - that is, $\mu$ dollars of subsidy are given for every dollar in individual donations received by the organization. This is true, for example, of a substantial portion of the performing arts grants provided by the National Endowment for the Arts, and of some foundation and corporate grants as well. It is also the approach that characterizes what is by far the largest public performing arts subsidy program of all, namely, the deductibility of contributions under the federal personal income tax. ${ }^{26}$ Are such donation subsidies superior to lump-sum subsidies?

The general model. In making the comparison I shall assume, as seems empirically the case (Feldstein, 1975a and b; Feldstein and Clotfelter, 1976), that donations respond positively, if at all, to a matching subsidy. Thus, if

$n=\sqrt{q}[A-P]$ or equivalently the inverse demand function $P=A-n / \sqrt{ } q$, so that $P_{q n}>0$. Assume also that the firm's cost function takes the simple form $C=q+n$ and that the subsidy level $L$ is initially zero. Solving the first-order conditions for $q$ and $n$ and substituting these values into (19) gives $d S / d L=-1 /(2-\delta)$. Thus here $d S / d L<0$ for all values of $\delta$ between 0 and 1 . (In this example $d q / d L=2>0, d n / d L=2 /(A-1)>0$.)

Note that here $P-C_{n}=(A-1)[(1-\delta) /(2-\delta)]$, and therefore $P>C_{n}$ so long as $A$ $>1,0 \leq \delta<1$.

${ }^{25}$ For example, assume that an audience maximizer faces the demand and cost functions in the preceding footnote, and assume that initially $L=0$. Then $d S / d L=(2-5 \delta) / 3(2-\delta)$, so that $d S / d L<0$ for $\delta>2 / 5$. Here $P-C_{n}=(A-1)(2-3 \delta) / 3(2-\delta)$, so $P>C_{n}$ whenever $\delta<2 / 3$ and $A>1$. In this case (assuming $A>1)$, $d n / d L=3 /(A-1)>0, d q / d L=4 / 3>0$, $S_{n}=(A-1)(2-3 \delta) / 3(2-\delta)>0$ for $\delta<2 / 3$ and $S_{n}<0$ for $1 \geq \delta>2 / 3, S_{q}=-(1-\delta) /(2-\delta)$ $<0$ for $0 \leq \delta<1$.

${ }^{26}$ Netzer $(1978$, pp. 44,95$)$ estimates the cost to the federal government of the deduction for gifts to arts organizations as $\$ 400$ million or more, while he estimates total direct public support of the arts at all governmental levels as just under $\$ 300$ million for 1975 . 
$\mu$ is the rate at which donations are matched, then $D=D(n, q, \mu), \partial D / \partial \mu>0$. In particular, I shall sometimes assume (as a special case of (1)) that

$$
D(n, q, \mu)=\delta(\mu)\left[\int_{0}^{n} P(v, q) d v-n P(n, q)\right],
$$

where $\delta^{\prime}(\mu)>0$.

With a donation subsidy at a rate $\mu$, the firm's nonprofit constraint becomes

$$
N R=n P(n, q)+(1+\mu) D(n, q, \mu)-C(n, q)=0 .
$$

If the firm maximizes $U(n, q)$ subject to this constraint, the first-order conditions are, in addition to (27),

$$
\begin{gathered}
P+n P_{n}+(1+\mu) D_{n}-C_{n}=-\frac{U_{n}}{\lambda} \\
n P_{q}+(1+\mu) D_{q}-C_{q}=-\frac{U_{q}}{\lambda},
\end{gathered}
$$

where $\lambda$ is a Lagrange multiplier.

Proceeding as in the case of the lump-sum subsidy, we can evaluate the effect of an increase in the subsidy rate $\mu$ on $n, q$, and $S$ by differentiating (27)-(29) with respect to $\mu$, solving for $d n / d \mu$ and $d q / d \mu$, and then determining $d S / d \mu$ by means of

$$
\frac{d S}{d \mu}=S_{q} \frac{d q}{d \mu}+S_{n} \frac{d n}{d \mu}=\left[\int_{0}^{n} P_{q}(v, q) d v-C_{q}\right] \frac{d q}{d \mu}+\left[P-C_{n}\right] \frac{d n}{d \mu} .
$$

The quality maximizer. For the quality maximizer we have

$$
\begin{aligned}
& \frac{d q}{d \mu}=\frac{d q}{d L}\left[D+\mu D_{\mu}\right]+\frac{d q}{d L} D_{\mu} \\
& \frac{d n}{d \mu}=\frac{d n}{d L}\left[D+\mu D_{\mu}\right]+\frac{d n}{d L} D_{\mu}-\frac{1}{N R_{n n}}\left[D_{n}+(1+\mu) D_{n \mu}\right] \\
& \frac{d S}{d \mu}=\frac{d S}{d L}\left[D+\mu D_{\mu}\right]+\frac{d S}{d L} D_{\mu}-\frac{\left(P-C_{n}\right)}{N R_{n n}}\left[D_{n}+(1+\mu) D_{n \mu}\right],
\end{aligned}
$$

where $d q / d L, d n / d L$, and $d S / d L$ are the effects upon $q, n$, and $S$ of a one-dollar lump-sum subsidy as given above by (21), (20), and (19), respectively.

Here $D_{\mu} \equiv \partial D / \partial \mu>0$ reflects the increase in private donations induced by the increase in the matching rate $\mu$. (In the case of $(26), D_{\mu}=\left(\delta^{\prime} / \delta\right) D$.) The expression $D+\mu D_{\mu}$ gives the dollar increase in expenditure on the subsidy associated with a unit increase in $\mu$. The first term on the right-hand side of (31)-(33) reflects the direct effect of the increase $D+\mu D_{\mu}$ in expenditure on the subsidy; this effect has the same sign and magnitude as would an equivalent expenditure on a lump-sum subsidy, as analyzed above. The second term on the right-hand side of (31)-(33) reflects the additional effect resulting from the increase in private donations induced by increasing $\mu$.

Turning to the third term on the right-hand side of (32), we have, using the donation function (26),

$$
D_{n}+(1+\mu) D_{n \mu}=-\left[\delta+(1+\mu) \delta^{\prime}\right] n P_{n} .
$$


This expression is positive, and thus, since $N R_{n n}<0$ by virtue of the secondorder condition, the final term in (32) is positive. This term reflects the incentive to increase $n$ (and lower $P$ ) given to the firm by virtue of the fact that, with a higher $\mu$, the firm will effectively be able to capture a larger fraction of the increase in consumer surplus created by such a move. The final term in (33) derives from the increase in $n$ reflected in the final term in (32), and will be positive whenever $P>C_{n}$.

It follows from (33) that, in terms of our welfare measure $S$, a donation subsidy will always be superior to an equivalent expenditure on a lumpsum subsidy in any case in which a lump-sum subsidy would itself be justifiable (i.e., where $d S / d L>0$ ). The extent by which the donation subsidy dominates an equivalent lump-sum subsidy is given by the second and third terms on the right-hand side of (33), reflecting, respectively, the increase in private donations and the increase in the donation matching rate $\mu$.

The audience maximizer. For the audience maximizer we have

$$
\begin{aligned}
& \frac{d q}{d \mu}=\frac{d q}{d L}\left[D+\mu D_{\mu}\right]+\frac{d q}{d L} D_{\mu}-\frac{N R_{q \mu}}{N R_{q q}} \\
& \frac{d n}{d \mu}=\frac{d n}{d L}\left[D+\mu D_{\mu}\right]+\frac{d n}{d L} D_{\mu} \\
& \frac{d S}{d \mu}=\frac{d S}{d L}\left[D+\mu D_{\mu}\right]+\frac{d S}{d L} D_{\mu}+\left[\int_{0}^{n} P_{q}(v, q) d v-n P_{q}\right] \frac{-N R_{q \mu}}{N R_{q q}},
\end{aligned}
$$

where $d q / d L, d n / d L$, and $d S / d L$ are the effects of a unit increase in the lump-sum subsidy as given by (24), (23), and (19).

The interpretation of the first two terms on the right-hand side of (35)-(37) parallels that given for (31)-(33) above. Using the donation function (26), the final term in $(35)$ becomes

$$
\frac{-N R_{q \mu}}{N R_{q q}}=\frac{-\left[\delta+(1+\mu) \delta^{\prime}\right]\left[\int_{0}^{n} P_{q}(v, q) d v-n P_{q}\right]}{N R_{q q}},
$$

which has the same sign as $P_{q n}$ (since $N R_{q q}<0$ by virtue of the second-order condition). This term reflects the increased incentive to adjust quality to conform to the tastes of inframarginal donors that the firm faces owing to the larger fraction of consumer surplus that it can (in effect) capture with a higher value of $\mu$. The final term in (37) reflects the same phenomenon. Using (26), that term becomes

$$
\begin{aligned}
{\left[\int_{0}^{n} P_{q}(v, q) d v-n P_{q}\right] \frac{-N R_{q \mu}}{N R_{q q}} } & \\
& =-\frac{\left[\delta+(1+\mu) \delta^{\prime}\right]\left[\int_{0}^{n} P_{q}(v, q) d v-n P_{q}\right]}{N R_{q q}} .
\end{aligned}
$$

This term will always be nonnegative, reflecting the fact that bringing quality more into line with average, as opposed to marginal, audience members will always enhance consumer welfare as measured by $S$. 
It follows from (37), then, that whenever $d S / d L \geq 0$, a lump-sum subsidy is dominated by a donation subsidy of equivalent amount - or, in other words, for the audience maximizer as for the quality maximizer, a donation subsidy is to be preferred to a lump-sum subsidy whenever a subsidy of either type is justifiable at all.

Summary. The advantages of the donation subsidy here are two-fold. First, by inducing further donations it yields to the firm a larger increase in revenue per dollar of subsidy than does the lump-sum subsidy. Note, in this connection, that since part of the increased revenues due to a donation subsidy come from donors who benefit from-and value highly - the performances involved, donation subsidies also have stronger equitable appeal than do lumpsum subsidies, at least where public funds are the source of the subsidy. ${ }^{27}$

Second, a subsidy geared to donations gives the firm an additional incentive to attract donations. Since we have been assuming that donations are proportional to consumer surplus, this means that with a donation subsidy the firm has an incentive to adjust its quality and price (or, equivalently here, audience size) closer to the levels that maximize consumer welfare.

\section{Ticket subsidies and taxes}

Admissions subsidies for the performing arts might also seem attractive (Netzer, 1978, pp. 32-33). Such subsidies might take either of two forms. First, the subsidy can be offered on the basis of a fixed amount per admission, regardless of the price charged for admission. Second, the subsidy can be designed to match total admissions (ticket) receipts on a fixed percentage basis, similar to the donation subsidy discussed above. In both cases incentives will be created for the organization that are absent in the case of a lump-sum subsidy.

At present neither of these types of admission subsidies is common. However, a negative subsidy applied to total ticket receipts, in the form of a sales tax on theater tickets, has commonly been applied to commercial performing arts groups and sometimes to nonprofit organizations as well. Since the effects of such a tax are precisely the reverse of those resulting from a subsidy of the same type, analysis of the subsidy also yields an analysis of the tax.

The model. I shall confine myself here to analysis of a per-receipts subsidy. Rather similar results follow from an analysis of a subsidy of a fixed amount per admission.

Let $\sigma$ represent the rate at which ticket receipts are matched by the ticket receipts subsidy, so that the total amount expended through this subsidy is $\sigma n P$. The firm's nonprofit constraint becomes

$$
(1+\sigma) n P+D-C=0 .
$$

The quality maximizer. Proceeding as in the analysis of the donation sub-

${ }^{27}$ The donation subsidy modeled here has a matching rate $\mu$ that does not vary from one donor to another - as would be the case with a uniform tax credit, and as is typically the case with NEA grants. The subsidies channeled through the charitable deduction under the personal income tax, in contrast, involve a matching rate that ranges from $0 \%$ to $70 \%$ depending upon the donor's tax bracket. Such a deduction may well be dominated, in terms of both equity and efficiency, by a tax credit of equivalent amount. See Hochman and Rodgers (1977). 
sidy, the effects of increasing the ticket subsidy rate for the quality maximizer are:

$$
\begin{aligned}
& \frac{d q}{d \sigma}=\frac{d q}{d L} n P \\
& \frac{d n}{d \sigma}=\frac{d n}{d L} n P-\frac{P+n P_{n}}{N R_{n n}} \\
& \frac{d S}{d \sigma}=\frac{d S}{d L} n P-\left(P-C_{n}\right) \frac{P+n P_{n}}{N R_{n n}} .
\end{aligned}
$$

The expression $n P$ here represents the dollar increase in expenditure on the ticket subsidy associated with a unit increase in $\sigma$. The first term on the right-hand side in (41)-(43) gives the direct effect of the increase $n P$ in the amount of the subsidy; it is the same as the effect of an equivalent expenditure on a lump-sum subsidy. The final term in (42) will be positive if the firm is operating where demand is elastic $\left(n P_{n} / P>-1\right)$, and negative otherwise, reflecting the fact that the net-revenue-maximizing value of $n$ (which is the value of $n$ chosen by the quality maximizer) changes with $\sigma$. It follows from (42) that a ticket subsidy will actually lead to a smaller increase in audience size (and thus, from (43), a smaller increase in welfare) than would an equivalent lumpsum subsidy if (as is possible) the quality maximizer is operating in the inelastic portion of the demand curve. ${ }^{28}$

The audience maximizer. For the audience maximizer we have

$$
\begin{aligned}
& \frac{d q}{d \sigma}=\frac{d q}{d L} n P-\frac{n P_{q}}{N R_{q q}} \\
& \frac{d n}{d \sigma}=\frac{d n}{d L} n P \\
& \frac{d S}{d \sigma}=\frac{d S}{d L} n P-\left[\int_{0}^{n} P_{q}(v, q) d v-n P_{q}\right] \frac{n P_{q}}{N R_{q q}} .
\end{aligned}
$$

Since $n P_{q} / N R_{q q}<0$, it follows from (44) that a ticket subsidy will lead to a larger increase in quality than will an equivalent expenditure on a lump-sum subsidy. The reason for this is that increasing $\sigma$ increases $P_{q}$, and hence raises the level of $q$ that maximizes net revenue. As the final term in (46) indicates, this (additional) increase in $q$ will raise, rather than lower, welfare only if $P_{q n}<0$.

Summary. Interestingly, for the audience-maximizing firm a ticket subsidy has no greater effect on audience size than does a lump-sum subsidy, while for the quality maximizer a ticket subsidy may actually lead to a smaller audience than would a lump-sum subsidy. For both the audience maximizer and the quality maximizer, there is a range of cases in which a ticket subsidy is dominated by a lump-sum subsidy in terms of our welfare measure $S$. From the results in Section 6 we can in turn conclude that there is a much larger class of cases in which a ticket subsidy is dominated by a donation subsidy-

${ }^{28}$ In the model developed here, the quality maximizer will operate where $n P_{n} / P<-1$ when marginal cost $\left(C_{n}\right)$ is low and the increase in donations $\left(D_{n}\right)$ in response to lower ticket prices is relatively large (see (5)). 
though there may be instances in which a ticket subsidy is superior to both donation and lump-sum subsidies.

\section{Conclusion}

The live performing arts are commonly characterized by fixed costs that are high relative to marginal costs, and by overall demand that is relatively small. As a consequence, performing arts groups often must engage in price discrimination if they are to survive without subsidy. The opportunities for effective discrimination through ticket pricing are limited, however. Therefore, nonprofit firms, which can, in effect, employ a system of voluntary price discrimination, can often survive in areas of the performing arts where forprofit firms cannot.

In many cases, free-rider incentives presumably keep donations below the level necessary for efficient production. In such cases, public subsidies can be justified on efficiency grounds, although such subsidies clearly present problems of equity.

As it is, the arts in the United States, including the performing arts, receive public subsidies that compare favorably in amount with those provided in other industrialized democracies (Netzer, 1978, pp. 50-52). The United States is unique, however, in providing most of its public subsidies in the form of matching grants for private donations. This policy has a great deal to recommend it. Donation subsidies not only serve to increase the level of private contributions, but may also cause performing arts groups to pay greater attention to the desires of inframarginal consumers.

\section{References}

Baumol, W.J. ANd Bowen, W.G. Performing Arts: The Economic Dilemma. Cambridge: Harvard University Press, 1968.

Brustein, R. "The Metropolitan Opera-The High Price of Being Best." New York Times (February 12, 1978, Section 2, cols. 1 and 6).

Feldstein, M. "Hospital Price Inflation: A Study of Nonprofit Price Dynamics." American Economic Review, Vol. 61, No. 5 (December 1971), pp. 853-872.

- "The Income Tax and Charitable Contributions: Part I-Aggregate and Distributional Effects." National Tax Journal, Vol. 28 (1975), pp. 81-99.

- "The Income Tax and Charitable Contributions: Part II - The Impact on Religious, Educational, and Other Organizations." National Tax Journal, Vol. 28 (1975), pp. 209-226.

- and Clotfelter, C. "Tax Incentives and Charitable Contributions in the United States." Journal of Public Economics, Vol. 5 (1976), pp. 1-26.

Ford Foundation. The Finances of the Performing Arts. New York: 1974.

Globerman, S. AND Book, S.H. "Statistical Cost Functions for Performing Arts Organizations." Southern Economic Journal, Vol. 40 (April 1974), pp. 668-671.

Gordon, D. "Why the Movie Majors are Major" in T. Balio, ed., The American Film Industry, Madison: University of Wisconsin Press, 1976.

HansmanN, H. "The Role of Nonprofit Enterprise." Yale Law Journal, Vol. 89 (April 1980), pp. 835-901.

Hochman, H. and Rodgers, J. "The Optimal Tax Treatment of Charitable Contributions." $\mathrm{Na-}$ tional Tax Journal, Vol. 30 (March 1977), pp. 1-18.

MAYernik, M. "Rhapsody in Red: The Economic Future of the Philadelphia Orchestra." Unpublished manuscript, Department of Economics, University of Pennsylvania, Spring 1976.

Moore, T.G. The Economics of the American Theater. Durham: University of North Carolina Press, 1968.

National Endowment for the Arts. Annual Report. 1978.

Netzer, R. The Subsidized Muse. Cambridge: Cambridge University Press, 1978. 
Newhouse, J. "Toward a Theory of Nonprofit Institutions: An Economic Model of a Hospital." American Economic Review, Vol. 60, No. 1 (March 1970), pp. 64-74.

Oı, W. "A Disneyland Dilemma: Two-Part Tariffs for a Mickey Mouse Monopoly." Quarterly Journal of Economics, Vol. 85 (February 1971), pp. 77-96.

Peacock, A.T. "Welfare Economics and Public Subsidies to the Arts" in M. Blaug, ed., The Economics of the Arts, London: Westview, 1976.

Rockefeller Brothers Fund. The Performing Arts: Problems and Prospects. New York, 1965.

SheshinsKI, E. "Price, Quality and Quantity Regulation in Monopoly Situations." Economica, Vol. 43 (May 1976), pp. 127-137.

SPEnCE, A.M. “Monopoly, Quality, and Regulation." Bell Journal of Economics, Vol. 6, No. 2 (Autumn 1975), pp. 417-429.

WeISBROD, B.A. "Toward a Theory of the Voluntary Nonprofit Sector in a Three-Sector Economy" in E. Phelps, ed., Altruism, Morality, and Economic Theory, New York, 1975.

Winter, S. “A Problem.” Unpublished manuscript, May 1968. 